\title{
Comparison of clinical features between non- smokers with COPD and smokers with COPD: a retrospective observational study
}

This article was published in the following Dove Press journal:

International Journal of COPD

8 January 2014

Number of times this article has been viewed

Jing Zhang*
Xin-feng Lin*
Chun-xue Bai

Department of Pulmonary Medicine, Zhongshan Hospital, Shanghai Medical College, Fudan University, Shanghai, People's Republic of China

*These authors contributed equally to this paper
Correspondence: Chun-xue Bai I80 Fenglin Road, Department of Pulmonary Medicine, Zhongshan Hospital, Shanghai, 200032, People's Republic of China Email bai.chunxue@zs-hospital.sh.cn
Background: Smoking is a major risk factor for chronic obstructive pulmonary disease (COPD); however, the similarities and differences in clinical presentation between smokers and nonsmokers are not fully described in patients with COPD. This study was designed to address this issue in a general teaching hospital in the People's Republic of China.

Methods: The medical records of patients hospitalized with a lung mass for further evaluation at Zhongshan Hospital, Fudan University, from January 2006 to December 2010 were reviewed and the data of interest were collected. The definition of COPD was according to Global Initiative for Chronic Obstructive Lung Disease (GOLD) spirometric criteria. Participants who had a previous exacerbation within 4 weeks of admission, airflow limitation due to abnormalities in the large airways, or with other pulmonary diseases were excluded. Included subjects were divided into nonsmokers with COPD and smokers with COPD by a cutoff of a 5 pack-year smoking history.

Results: A total of 605 subjects were included in the final analysis. The average age was $64.8 \pm 8.5$ years and $62.0 \%(375 / 605)$ were smokers. Eighty percent of the patients had mild to moderate disease (GOLD grade 1-2). Age and years with COPD were comparable between the two groups. Compared with smokers with COPD, nonsmokers with COPD were more likely to be female, reported less chronic cough and sputum, have less emphysema on radiologic examination, and higher measures of forced expiratory volume in the first second percent predicted ( $\left.\mathrm{FEV}_{1}\right)$, forced expiratory volume in one second/forced vital capacity $\left(\mathrm{FEV}_{1} / \mathrm{FVC} \%\right.$ ) percent predicted, maximal voluntary ventilation percent predicted, diffusing capacity of lung (DLCO) percent predicted, and DLCO/alveolar volume percent predicted, with lower levels of residual volume percent predicted and residual volume/total lung capacity percent predicted. There were no significant differences between the two groups with regard to distribution of disease severity, vital capacity percent predicted, total lung capacity percent predicted, $\mathrm{PaO}_{2}, \mathrm{PaCO}_{2}$, modified Medical Research Council dyspnea score, wheezing, airway reversibility, and comorbidities. Smoking amount (pack-years) was correlated negatively with $\mathrm{FEV}_{1}$ percent predicted, $\mathrm{FEV}_{1} / \mathrm{FVC} \%$ percent predicted, inspiratory capacity percent predicted, inspiratory capacity/total lung capacity percent predicted, and DLCO percent predicted, and correlated positively with GOLD grade and symptoms.

Conclusion: Non-smokers with COPD had less impairment in airflow limitation and gas exchange, and a lower prevalence of emphysema, chronic cough, and sputum compared with their smoking counterparts. Tobacco cessation is warranted in smokers with COPD.

Keywords: chronic obstructive pulmonary disease, smokers, non-smokers, lung function, symptoms, emphysema

\section{Introduction}

Chronic obstructive pulmonary disease (COPD) is one of the leading causes of morbidity and mortality worldwide, and represents a huge and growing economic and 
social burden. ${ }^{1}$ It is characterized by chronic inflammation and irreversible airflow obstruction, involving structural changes in the lung. ${ }^{2}$ Tobacco smoking is the most important risk factor for the development of COPD; ${ }^{1}$ however, not all patents with COPD have a history of smoking. As little as $50 \%$ of cases worldwide are related to smoking, ${ }^{3}$ and an estimated $10 \%-12 \%$ of individuals with COPD have never smoked. ${ }^{4}$ In other words, irreversible airflow obstruction also occurs in never smokers. Analysis of data from the international, population-based Burden of Obstructive Lung Disease (BOLD) study showed that $23.3 \%$ of subjects with Global Initiative for Chronic Obstructive Lung Disease (GOLD) grade 2-4 COPD were never smokers. ${ }^{4}$ In the People's Republic of China, a large survey including 20,245 participants reported by Zhong et $\mathrm{al}^{5}$ in 2007 showed that the prevalence of COPD in those aged over 40 years was $8.2 \%$, and $38.6 \%$ of those with COPD were non-smokers. In addition to tobacco smoking, COPD in the People's Republic of China is related to exposure to biomass and occupational dusts/gases/fumes, pulmonary problems in childhood, family history of respiratory disease, low educational level, poor socioeconomic status, aging, lower body mass index, poor ventilation in the kitchen, age, and genetic susceptibility. ${ }^{6,7}$

While population-based studies have confirmed an incidence of COPD in non-smokers, few detailed studies have been performed in this population. For example, the classic study on the natural history of COPD by Fletcher et $\mathrm{al}^{8}$ excluded non-smokers and thus no information was provided for subjects without a history of smoking but with chronic irreversible airflow obstruction. Participants in clinical trials are also limited to smokers with COPD. Therefore, little is known about the clinical features of non-smokers with COPD or their differences and similarities compared with smokers who have COPD.

To address this issue, we undertook a retrospective observational study to investigate the differences in clinical presentation between non-smokers with COPD and smokers with COPD, including their respiratory symptoms, impaired lung function, and radiologic changes.

\section{Materials and methods}

This study was approved by the ethics committee of Zhongshan Hospital, Fudan University, where medical records were retrospectively reviewed.

\section{Study population}

Medical records for patients hospitalized at Zhongshan Hospital with a lung mass requiring further evaluation from January 2006 to December 2010 were retrospectively reviewed, and those with COPD were entered into this study. Respiratory physicians who had received standardized training were responsible for review of the records and data collection.

Participants who had had an exacerbation within 4 weeks of admission were excluded. Subjects with other lung diseases such as pulmonary tuberculosis, bronchiectasis, pneumosilicosis, interstitial lung disease, or pleural effusion, or a history of pneumonectomy were also excluded, as were patients who had airflow limitation due to abnormalities in the large airways.

\section{Definitions}

Lung function tests were performed routinely on admission for patients hospitalized with a lung mass before making a treatment plan. The lung function tests had been performed according to international guidelines using calibrated MSPFT equipment (Jaeger Co, Würzburg, Germany). The diagnosis of COPD was according to the GOLD definition. Briefly, COPD was considered to be present if post-bronchodilator forced expiratory volume in the first second of expiration $\left(\mathrm{FEV}_{1}\right)$ /forced vital capacity $(\mathrm{FVC})$ ratio was less than $0.70 .{ }^{9}$ The grade of COPD based on $\mathrm{FEV}_{1}$ was classified as shown in Table 1. Significant bronchodilator reversibility was defined as an increase in $\mathrm{FEV}_{1}$ or FVC of at least $12 \%$ and $200 \mathrm{~mL}$, respectively, from baseline values. Non-smokers were defined as having $<5$ pack-years of tobacco exposure; otherwise, the subjects were classified as smokers.

\section{Data collection}

The following information was collected: patient age, sex, smoking status (never smoker, ever smoker, current

Table I Definition and severity grading of COPD according to airflow obstruction

\begin{tabular}{ll}
\hline Grade & $\begin{array}{l}\text { Post-bronchodilator } \\
\text { spirometry }\end{array}$ \\
\hline Grade I (Mild COPD) & $\mathrm{FEV} / \mathrm{FVC}<70 \%$; FEV,$\%$ pred $\geq 80 \%$ \\
Grade 2 (Moderate COPD) & $\mathrm{FEV} / \mathrm{FVC}<70 \% ; 50 \% \leq \mathrm{FEV}, \%$ pred \\
& $<80 \%$ \\
Grade 3 (Severe COPD) & $\mathrm{FEV} / \mathrm{FVC}<70 \% ; 30 \% \leq \mathrm{FEV}, \%$ pred \\
& $<50 \%$ \\
Grade 4 (Very severe COPD) & $\mathrm{FEV} / \mathrm{FVC}<70 \% ; \mathrm{FEV}, \%$ pred $<30 \%$ \\
& or FEV $\%$ pred $<50 \%$ plus chronic \\
& respiratory failure \\
\hline
\end{tabular}

Notes: Adapted by the author from the "Global Strategy for Diagnosis, Management and Prevention of COPD, 2013" Global initiative for Chronic Obstructive Lung Disease (GOLD), available from http://www.goldcopd.org.'

Abbreviations: COPD, chronic obstructive pulmonary disease; FEV , forced expiratory volume in one second; FVC, forced vital capacity; \%pred, percentage of predicted. 
smoker), quantity of tobacco smoking exposure (pack-years), respiratory symptoms (chronic cough, chronic sputum, a history of/or concurrent wheezing), modified Medical Research Council dyspnea score, and comorbidity (hypertension, coronary heart disease, diabetes). Lung function test values and results of arterial blood gas analysis were collected. Computed tomographic scan images were retrieved from Picture Archiving and Communication Systems and examined independently by two radiologists, and emphysema was qualitatively recorded. The treatment given for COPD was also investigated, and conformity with GOLD guidelines was evaluated. Two authors independently reviewed the medical records of all included cases. Any discrepancies were resolved by discussion with a referee to reach a final consensus.

\section{Statistical analysis}

The data for continuous variables are expressed as the mean \pm standard deviation, and bivariate analysis were performed using unpaired $t$-tests and Pearson correlation. For discrete variables and ranked variables, a Chi-squared $\left(\chi^{2}\right)$ test and Spearman rank correlation analysis, respectively, were used. Multiple logistic regression was used to analyze differences in symptoms after adjusing for FEV $\mathrm{F}_{1}$. All statistical analyses were performed using Statistical Package for the Social Sciences version 19.0 (SPSS Inc, Chicago, IL, USA). Values were considered to be statistically significant at $P<0.05$.

\section{Results}

\section{Demographic data}

A total of 643 patients with stable COPD during the study period were reviewed, and 605 were included in the final analysis after excluding 38 cases with tuberculosis $(n=33)$, bronchiectasis $(n=2)$, pneumosilicosis $(n=2)$, and pneumonectomy $(n=1)$. The average age was $64.8 \pm 8.5$ years, and 532 $(87.9 \%)$ were males. In this cohort, the smoking prevalence in males was $70.3 \%(374 / 532)$, which was significantly higher than that in females $\left(1.4 \%, 1 / 73, \chi^{2}=129.4, P<0.001\right)$. Overall, among all the patients with COPD, 18.8\%, 61.2\%, $17.7 \%$, and $2.3 \%$, respectively, had mild (GOLD grade 1 ), moderate (grade 2 ), severe (grade 3 ), and very severe disease (grade 4).

The characteristics of COPD patients with and without a smoking history are summarized in Table 2. Of all the 605 subjects, $375(62.0 \%)$ had a history of smoking (three ex-smokers and 372 current smokers). Age and years with COPD, ie, years since diagnosis of COPD, were comparable between the two groups. Smokers with COPD were more
Table 2 Demographic data

\begin{tabular}{llll}
\hline & $\begin{array}{l}\text { Non-smokers } \\
\text { with COPD } \\
(\mathbf{n}=230)\end{array}$ & $\begin{array}{l}\text { Smokers } \\
\text { with COPD } \\
(\mathbf{n = 3 7 5 )}\end{array}$ & P-value \\
\hline Age (years) & $65.1 \pm 9.2$ & $64.7 \pm 8.1$ & 0.574 \\
Male sex, n\% & $158,68.7 \%$ & $374,99.7 \%$ & $<0.001$ \\
$\begin{array}{l}\text { Tobacco exposure } \\
\text { (pack-years) }\end{array}$ & $0.07 \pm 0.52$ & $45.26 \pm 26.4 \mathrm{I}$ & $<0.00 \mathrm{I}$ \\
\hline
\end{tabular}

Abbreviation: COPD, chronic obstructive pulmonary disease.

likely to be men. Average tobacco exposure in smokers with COPD was about 45 pack-years.

\section{Lung function parameters}

$\mathrm{FEV}_{1}$ and $\mathrm{FVC}$ were significantly lower in non-smokers with COPD than in smokers with COPD (Table 3); however, the percentage of males was much lower in non-smokers than in smokers, which might account for these differences. After adjusting for sex and age, the differences in $\mathrm{FEV}_{1}$ and $\mathrm{FVC}$ between the two groups became nonsignificant, with $P$-values of 0.432 and 0.593 , respectively. To avoid the confounding effect of the sex difference between non-smokers and smokers, percent predicted was used to analyze and present lung function parameters.

Table 3 Comparisons of lung function and arterial blood gas values between non-smokers and smokers with COPD

\begin{tabular}{|c|c|c|c|}
\hline & $\begin{array}{l}\text { Non-smoker } \\
\text { COPD } \\
(n=230)\end{array}$ & $\begin{array}{l}\text { Smoker } \\
\text { COPD } \\
(n=375)\end{array}$ & $P$-value \\
\hline $\mathrm{FEV}_{1}(\mathrm{~L})$ & $1.713 \pm 0.522$ & $1.845 \pm 0.58 \mid$ & 0.005 \\
\hline FEV, \%pred & $65.9 \pm 16.7$ & $62.6 \pm 17.2$ & 0.021 \\
\hline FEV,$\%$ pred $<50 \%$, n (\%) & $37(16.1 \%)$ & $84(22.4 \%)$ & 0.060 \\
\hline $\mathrm{FVC}(\mathrm{L})$ & $2.738 \pm 0.739$ & $2.994 \pm 0.754$ & $<0.001$ \\
\hline FVC \%pred & $81.9 \pm 16.9$ & $80.4 \pm 18.2$ & 0.316 \\
\hline $\mathrm{FEV}_{\mathrm{I}} / \mathrm{FVC}(\%)$ & $62.1 \pm 6.7$ & $60.8 \pm 7.6$ & 0.037 \\
\hline MVV \%pred & $61.9 \pm 14.6$ & $58.5 \pm 13.9$ & 0.004 \\
\hline RV \%pred & $101.9 \pm 28.9$ & $107.0 \pm 31.2$ & 0.044 \\
\hline TLC \%pred & $86.7 \pm 15.1$ & $87.0 \pm 14.0$ & 0.808 \\
\hline RV/TLC \%pred & $115.9 \pm 21.4$ & $120.0 \pm 23.5$ & 0.042 \\
\hline IC \%pred & $82.3 \pm 20.4$ & $80.8 \pm 19.1$ & 0.369 \\
\hline IC/TLC (\%) & $42.1 \pm 9.1$ & $40.7 \pm 8.7$ & 0.054 \\
\hline DLCO \%pred & $67.3 \pm 19.3$ & $61.9 \pm 18.8$ & 0.001 \\
\hline DLCO/VA (\%) & $65.9 \pm 17.4$ & $61.2 \pm 18.6$ & 0.002 \\
\hline VC \%pred & $81.7 \pm 16.6$ & $80.3 \pm 17.1$ & 0.298 \\
\hline $\mathrm{pH}$ value & $7.42 \pm 0.28$ & $7.42 \pm 0.29$ & 0.734 \\
\hline $\mathrm{PaO}_{2}(\mathrm{mmHg})$ & $80.5 \pm 11.2$ & $81.4 \pm 11.7$ & 0.332 \\
\hline $\mathrm{PaCO}_{2}(\mathrm{mmHg})$ & $40.7 \pm 3.9$ & $40.9 \pm 3.6$ & 0.528 \\
\hline
\end{tabular}

Abbreviations: COPD, chronic obstructive pulmonary disease; FEV, forced expiratory volume in first second of expiration; FVC, forced vital capacity; MVV, maximum ventilation volume; RV, residual volume; TLC, total lung capacity; IC, inspired capacity; DLCO, diffusing capacity of lung; VA, alveolar volume; VC, vital capacity; \%pred, percent predicted. 
$\mathrm{FEV}_{1}$ percent predicted was higher in non-smokers with COPD than in smokers with COPD $(P=0.021$, Table 3$)$. Although there was no significant difference in distribution of COPD grades between the two groups (Figure 1), the quantity of tobacco smoked (pack-years) was negatively correlated with $\mathrm{FEV}_{1}$ percent predicted $(P=0.009)$ and positively correlated with COPD grade $(P=0.024$, Table 4$)$. $\mathrm{FEV}_{1} / \mathrm{FVC} \%$ was higher in non-smokers with COPD, and was negatively related to pack-years.

Vital capacity percent predicted and total lung capacity (TLC) percent predicted were both over $80 \%$, and there was no difference between non-smokers with COPD and smokers with COPD. Therefore, the lower maximum ventilation volume percent predicted was another marker for poorer obstructive ventilatory function in smokers with $\mathrm{COPD}$. $\mathrm{PaCO}_{2}$ levels were similar between the two groups.

Compared with smokers with COPD, non-smokers with COPD showed a lower residual volume (RV) percent predicted $(P=0.044)$ and RV/TLC percent predicted $(P=0.042)$. Inspired capacity (IC) percent predicted and IC/TLC\% were higher for non-smokers with COPD, albeit not significantly so, but were negatively related to tobacco exposure $(P=0.018$ and $P=0.003$, respectively).

Diffusing capacity was also evaluated in our study. Diffusing capacity of lung (DLCO) percent predicted, serving as a predictor of pulmonary gas exchange, was higher for non-smokers with COPD than smokers with COPD $(P=0.001)$, and was negatively correlated with pack-years $(P<0.001)$. Diffusing capacity divided by alveolar volume remained significant. $\mathrm{PaO}_{2}$ levels were similar between the two groups.

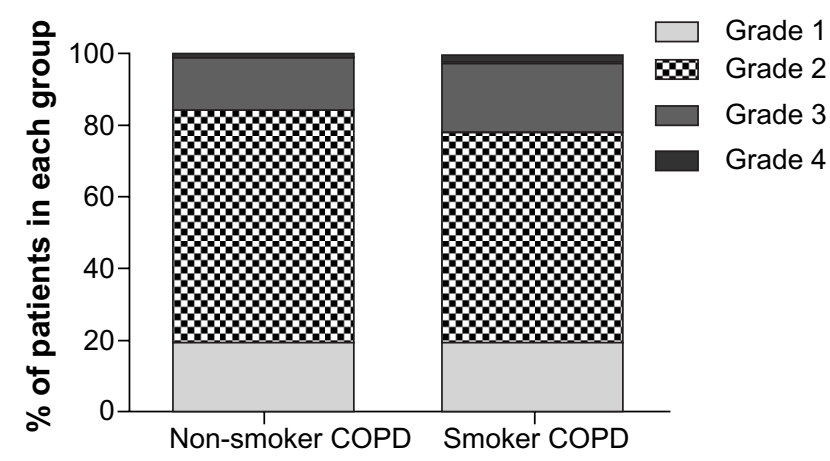

Figure I Distribution of COPD grading for non-smokers with COPD and smokers with COPD.

Notes: Grade I, FEV, \%pred $\geq 80 \%$; grade 2, $50 \% \leq \mathrm{FEV}, \%$ pred $<80 \%$; grade 3, $30 \% \leq$ FEV, \%pred $<50 \%$; grade 4 , FEV,$\%$ pred $<30 \%$ or $\mathrm{FEV}, \%$ pred $<50 \%$ plus chronic respiratory failure. Proportions of each grade in non-smokers with COPD versus smokers with COPD were as follows: grade I, $20.4 \%$ versus $17.9 \%$; grade 2, $63.5 \%$ versus $59.7 \%$; grade $3,14.8 \%$ versus $19.5 \%$; and grade $4,1.3 \%$ versus $2.9 \%(P=0.064)$.
Table 4 Correlation analysis of lung function parameters with tobacco exposure (pack-years)

\begin{tabular}{lll}
\hline & Correlation $(\boldsymbol{r})$ & P-value \\
\hline FEV , \%pred & -0.107 & 0.009 \\
Grading & 0.091 & 0.024 \\
FVC \%pred & -0.072 & 0.078 \\
FEV,/FVC (\%) & -0.082 & 0.044 \\
MVV \%pred & -0.122 & 0.003 \\
RV \%pred & 0.068 & 0.097 \\
TLC \%pred & -0.006 & 0.887 \\
RV/TLC \%pred & 0.075 & 0.067 \\
IC \%pred & -0.097 & 0.018 \\
IC/TLC (\%) & -0.121 & 0.003 \\
DLCO \%pred & -0.183 & $<0.001$ \\
DLCO/VA (\%) & -0.164 & $<0.001$ \\
VC \%pred & -0.075 & 0.066 \\
\hline
\end{tabular}

Abbreviations: $\mathrm{FEV}_{1}$, forced expiratory volume in first second of expiration; FVC, forced vital capacity; MVV, maximum ventilation volume; RV, residual volume; TLC, total lung capacity; IC, inspired capacity; DLCO, diffusing capacity of lung; VA, alveolar volume; VC, vital capacity; \%pred, percent predicted.

\section{Respiratory symptoms}

Non-smokers with COPD had a significant lower prevalence of chronic cough and chronic sputum than smokers with

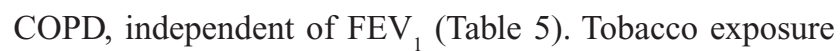
had a positive relationship with chronic cough and sputum, and the correlation remained significant after adjusting for FEV $_{1}$ (Table 6).

Non-smokers with COPD showed a trend towards less severe shortness of breath than smokers with COPD. As shown in Table 5, smoking exposure was significantly correlated with $\mathrm{mMRC}$ score after adjusting for $\mathrm{FEV}_{1}$.

\section{Asthma features}

Some asthmatic patients develop fixed airflow limitation, and some COPD patients may have comorbid asthma. We thus looked into features of asthma, which was confirmed by a history of wheezing or documented asthma and airway reversibility. In our study population, no differences were

Table 5 Comparisons of chronic cough, sputum, and dyspnea between non-smokers with COPD and smokers with COPD

\begin{tabular}{lllll}
\hline & $\begin{array}{l}\text { Non-smoker } \\
\text { COPD } \\
(\mathbf{n = 2 3 0 )}\end{array}$ & $\begin{array}{l}\text { Smoker } \\
\text { COPD } \\
(\mathbf{n = 3 7 5 )}\end{array}$ & P-value & $\begin{array}{l}\text { P-value } \\
\text { adjusted } \\
\text { for FEV }\end{array}$ \\
\hline $\begin{array}{l}\text { Chronic } \\
\text { cough, n (\%) }\end{array}$ & $19(8.3 \%)$ & $60(16 \%)$ & 0.006 & 0.001 \\
$\begin{array}{l}\text { Chronic } \\
\text { sputum, n (\%) }\end{array}$ & $19(8.3 \%)$ & $57(15.2 \%)$ & 0.016 & 0.002 \\
mMRC $>1, \mathrm{n}(\%)$ & $3(1.3 \%)$ & $8(2.1 \%)$ & 0.546 & 0.214 \\
\hline
\end{tabular}

Abbreviations: COPD, chronic obstructive pulmonary disease; $\mathrm{FEV}_{1}$, forced expiratory volume in first second of expiration; mMRC, modified Medical Research Council dyspnea score. 
Table 6 Correlation analysis of respiratory symptoms with tobacco exposure (pack-years)

\begin{tabular}{lllll}
\hline & Correlation $(\boldsymbol{r})$ & P-value & $\begin{array}{l}\text { Correlation }(\boldsymbol{r}) \\
\text { adjusted for FEV }\end{array}$ & $\begin{array}{l}\text { Correlation } \boldsymbol{P}_{\text {-value }} \\
(\mathbf{a d j u s t e d ~ f o r ~ F E V} \text { ) }\end{array}$ \\
\hline Chronic cough & 0.110 & 0.007 & 0.097 & 0.017 \\
Chronic sputum & 0.098 & 0.016 & 0.125 & 0.002 \\
mMRC score & 0.044 & 0.285 & 0.082 & 0.045 \\
mMRC $>$ I & 0.064 & 0.114 & 0.051 & 0.214 \\
\hline
\end{tabular}

Abbreviations: $\mathrm{FEV}_{1}$, forced expiratory volume in first second of expiration; mMRC, modified Medical Research Council dyspnea score.

found between non-smokers and smokers with COPD in this regard (Table 7).

\section{Emphysema on computed tomographic scan}

The prevalence of emphysema in non-smokers with COPD $(43 / 381,11.3 \%)$ was significantly lower than that in smokers with COPD $(9 / 225,4.0 \%, P<0.001)$.

\section{Treatment according to GOLD guidelines}

Less than $30 \%$ of the patients in this study were treated in accordance to GOLD recommendations. There was no difference in compliance with treatment between smokers with COPD $(101 / 375,26.9 \%)$ and non-smokers with COPD $(64 / 230,27.8 \%, P=0.851)$.

\section{Comorbidities}

The prevalence of comorbidities, including hypertension, diabetes, and coronary heart disease, was not significantly different between the two groups (Table 8). One smoker with COPD had documented depression; however, no other psychologic disorders were recorded.

\section{Discussion}

The current study provides a detailed description of impaired pulmonary function and symptoms of COPD in both never smokers and smokers. In spite of their comparable age and years since diagnosis, non-smokers with COPD showed less airflow limitation (higher levels of $\mathrm{FEV}_{1}, \mathrm{FEV}_{1} / \mathrm{FVC} \%$, and maximum ventilation volume) than smokers with $\mathrm{COPD}$.

Table 7 Comparisons of asthma features between non-smokers with COPD and smokers with COPD

\begin{tabular}{llll}
\hline & $\begin{array}{l}\text { Non-smoker } \\
\text { COPD } \\
(\mathbf{n = 2 3 0})\end{array}$ & $\begin{array}{l}\text { Smoker } \\
\text { COPD } \\
(\mathbf{n = 3 7 5 )}\end{array}$ & P-value \\
\hline $\begin{array}{l}\text { History of wheezing or } \\
\text { documented asthma, } \mathrm{n}(\%)\end{array}$ & $6(2.6 \%)$ & $7(1.9 \%)$ & 0.572 \\
Airway reversibility, $\mathrm{n}(\%)$ & $19(15.3 \%)$ & $32(16.8 \%)$ & 0.757 \\
\hline
\end{tabular}

Abbreviation: COPD, chronic obstructive pulmonary disease.
The chronic inflammatory process induced by tobacco smoking promotes thickening and narrowing of the small conducting airways, as well as destruction of the parenchyma and reduced alveolar-bronchiolar attachments. ${ }^{10-15}$ These additional changes could contribute to more severe expiratory airflow obstruction in smokers with COPD. Further, our findings that smokers with COPD tended to have more emphysema on radiologic examination and higher RV and poorer diffusing capacity on lung function testing are in line with evidence of extracellular matrix destruction induced by smoking. ${ }^{11,12,15,16}$

Chronic cough and sputum production, associated with an abundance of mucus-producing elements in the large airways, are major symptoms of COPD. ${ }^{1}$ In our study, smokers with COPD reported significantly more chronic cough and phlegm than never smokers, which is consistent with the knowledge that tobacco smoke is responsible for goblet cell hyperplasia and chronic hypersecretion of mucus. ${ }^{17,18}$

IC has been acknowledged to have a closer relationship with dyspnea than $\mathrm{FEV}_{1}{ }^{19,20}$ Also, the mMRC score was negatively correlated with IC percent predicted $(P<0.001)$ and IC/TLC\% $(P=0.032)$ in the current study. Smoking exposure (pack-years) was consistently and significantly correlated with mMRC score, although most of participants did not report apparent dyspnea.

Smoking is a known cause of COPD, chronic bronchitis, and emphysema, and the risk increases with pack-years. ${ }^{1,21}$ The relationship between smoking and decline in FEV

Table 8 Comparison of comorbidities between non-smokers with COPD and smokers with COPD

\begin{tabular}{llll}
\hline & $\begin{array}{l}\text { Non-smoker } \\
\text { COPD } \\
\text { (n=230) }\end{array}$ & $\begin{array}{l}\text { Smoker } \\
\text { COPD } \\
\text { (n=375) }\end{array}$ & P-value \\
\hline $\begin{array}{l}\text { Hypertension, diabetes, } \\
\text { and/or coronary heart }\end{array}$ & $59(25.7 \%)$ & II $3(30.1 \%)$ & 0.265 \\
$\begin{array}{l}\text { disease, } n \text { (\%) } \\
\text { Hypertension }\end{array}$ & $50(21.7 \%)$ & $96(25.6 \%)$ & 0.328 \\
$\begin{array}{l}\text { Coronary heart disease } \\
\text { Diabetes }\end{array}$ & $4(1.7 \%)$ & II $(2.9 \%)$ & 0.430 \\
\hline
\end{tabular}

Abbreviation: COPD, chronic obstructive pulmonary disease. 
has been well established in the general population. ${ }^{13,14,22}$ However, in patients with confirmed COPD, few studies have compared such changes between smokers and non-smokers. In the population-based BOLD study, ${ }^{4}$ it was reported that never smokers made up $27.7 \%(523 / 1,889)$ of all COPD cases, and $70.8 \%$ of non-smokers with COPD were female, which was significantly higher than the $37.0 \%$ of female smokers with COPD. The same pattern was evident in our study, but we noted that the proportion of males was much higher due to the fact that the prevalence of smoking in females is considerably low in the People's Republic of China. ${ }^{7}$ In another study of 30 smokers and seven never smokers with very severe COPD and chronic respiratory failure, the authors reported less emphysema and more bronchiectasis in non-smokers with COPD but no differences in $\mathrm{FEV}_{1}$, IC, body mass index, $\mathrm{mMRC}$ score, $\mathrm{SpO}_{2}$ at rest, use of long-term oxygen therapy, or 6-minute walking distance between the two groups. ${ }^{23}$ The failure to detect a difference was at least partly due to the late stage of the disease, when smoking status would have limited impact on these measures. Another possible explanation is their small sample size. Our study included all of the disease categories as defined by GOLD spirometric criteria and had a larger sample size. We demonstrated more severe airflow limitation and gas exchange, worse emphysema, and a poorer symptomatic profile in COPD patients with a smoking history than those without. It is of note that the majority of our study population had mild or moderate COPD, indicating the benefits of quitting smoking in the early stages of COPD, ie, improvement in respiratory symptoms and prevention of an excessive decline in $\mathrm{FEV}_{1} \cdot{ }^{24-27}$

It should be noted that the subjects in our study were hospitalized with a lung mass for further diagnosis and evaluation, and were likely to have had better lung function and fewer symptoms than a general COPD population. Subjects with GOLD grade 1 and grade 2 COPD comprised $18.8 \%$ $(114 / 605)$ and $61.2 \%(370 / 605)$ of our cohort, respectively. In a large epidemiologic study in the People's Republic of China, the prevalence of mild, moderate, severe, and very severe COPD was $2.0 \%, 3.8 \%, 1.7 \%$, and $0.4 \%$, respectively, with an overall prevalence of COPD of $8.2 \% .^{5}$ Additionally, $44 \%$ of subjects with COPD had cough, $30 \%$ had sputum, and $49 \%$ had dyspnea in that study. ${ }^{5}$ In comparison, $13.1 \%$, $11.3 \%, 1.8 \%$, and $2.1 \%$ of the patients in our cohort had chronic cough, chronic sputum, obvious dyspnea (ie, mMRC score $>1$ ), and wheezing, respectively. The study by Zhong et $\mathrm{al}^{5}$ involved seven cities from the east to west regions of the People's Republic of China and covered both urban and rural areas, and thus included a large variation in economic and health status, resulting in an imbalance in the prevalence of COPD and disease severity. In contrast, most of our patients were from the south-east urban area in and around Shanghai. This could also have contributed to the differences in severity and symptomatic patterns seen between the two studies.

Available epidemiologic data demonstrate that domestic biomass, fuel smoke, indoor air pollution, poor economic and social status, and existence of asthma might be important causes of COPD in never smokers, especially in women. ${ }^{6,7}$ A cluster sampling survey performed in populations aged over 40 years in Guangdong showed a significant relationship between COPD and exposure to biomass fuel for cooking. ${ }^{28}$ Another study from the Xuanwei District in Yunnan Province supports the association of indoor air pollution with COPD from another aspect. In that study, installation of chimneys on household coal stoves led to a substantial decrease in the incidence of COPD. ${ }^{29} \mathrm{~A}$ future cross-sectional and prospective cohort study should be performed to explore these risk factors and their impact on decline in lung function and worsening of respiratory symptoms.

There are several limitations to the current study that should be considered. First, it is a retrospective investigation, and data collection was based on medical records. Apart from smoking history, risk factors for COPD, such as occupation and indoor air pollution, were not analyzed because of incompleteness of data. Due to limitations in the clinical data that we could retrieve, we did not investigate nonsmokers with COPD using comprehensive indices like the BODE index or updated GOLD disease category. ${ }^{1}$ Second, our study subjects were patients who were hospitalized with a lung mass, which might have an impact on lung function and symptoms, and led to bias. To avoid the influence of lung mass on the comparisons made in our study, those with pleural effusion or airflow limitation due to abnormalities in the large airways were carefully excluded. Third, $80 \%$ of our subjects had mild to moderate disease, and sample sizes for each level of disease severity were not balanced, which affected our power to detect modest differences. This would also lead to weak statistically significant correlations in our analysis. Fourth, this was a cross-sectional study, whereas longitudinal follow-up cohort research is required to look into whether differences in lung function decline and treatment responses exist between smokers and nonsmokers with COPD.

Nevertheless, these limitations do not prevent the conclusion that non-smokers with COPD have less impairment of airflow limitation and gas exchange, and a lower prevalence of emphysema, chronic cough, and sputum compared with 
their smoking counterparts. Tobacco cessation is warranted in smokers with COPD.

\section{Acknowledgment}

This study was supported by the Zhuoxue Talents Scheme of Fudan University and received funding from the Shanghai Committee of Science and Technology (12411950100).

\section{Disclosure}

The authors declare no potential conflicts of interest with respect to the research, authorship, and/or publication on this article.

\section{References}

1. Global Initiative for Chronic Obstructive Lung Disease. Global Strategy for the Diagnosis, Management and Prevention of COPD, Global Initiative for Chronic Obstructive Lung Disease 2013. Available from: http://www.goldcopd.org/uploads/users/files/GOLD_Report_2013_ Feb20.pdf. Accessed July 20, 2013.

2. Balkissoon R, Lommatzsch S, Carolan B, Make B. Chronic obstructive pulmonary disease: a concise review. Med Clin North Am. 2011;95: $1125-1141$.

3. Eisner MD, Anthonisen N, Coultas D, et al. An official American Thoracic Society public policy statement: novel risk factors and the global burden of chronic obstructive pulmonary disease. Am J Respir Crit Care Med. 2010;182:693-718.

4. Lamprecht B, McBurnie MA, Vollmer WM, et al. COPD in never smokers: results from the population-based burden of obstructive lung disease study. Chest. 2011;139:752-763.

5. Zhong N, Wang C, Yao W, et al. Prevalence of chronic obstructive pulmonary disease in China: a large, population-based survey. Am J Respir Crit Care Med. 2007;176:753-760.

6. Fang X, Wang X, Bai C. COPD in China: the burden and importance of proper management. Chest. 2011;139:920-929.

7. Zhang J, Ou JX, Bai CX. Tobacco smoking in China: prevalence, disease burden, challenges and future strategies. Respirology. 2011;16: 1165-1172.

8. Fletcher C, Peto R. The natural history of chronic airflow obstruction. Br Med J. 1977;1:1645-1648.

9. Pellegrino R, Viegi G, Brusasco V, et al. Interpretative strategies for lung function tests. Eur Respir J. 2005;26:948-968.

10. Niewoehner DE, Kleinerman J, Rice DB. Pathologic changes in the peripheral airways of young cigarette smokers. $N$ Engl J Med. 1974;291 755-758.

11. Gietema HA, Edwards LD, Coxson HO, et al. Impact of emphysema and airway wall thickness on quality of life in smoking-related COPD. Respir Med. 2013;107:1201-1209.

12. Grydeland TB, Dirksen A, Coxson HO, et al. Quantitative computed tomography: emphysema and airway wall thickness by sex, age and smoking. Eur Respir J. 2009;34:858-365.
13. Lange $\mathrm{P}$, Groth $\mathrm{S}$, Nyboe J, et al. Decline of the lung function related to the type of tobacco smoked and inhalation. Thorax. 1990;45:22-26.

14. Xu X, Dockery DW, Ware JH, et al. Effects of cigarette smoking on rate of loss of pulmonary function in adults: a longitudinal assessment. Am Rev Respir Dis. 1992;146:1345-1348.

15. Murin S, Hilbert J, Reilly SJ. Cigaret smoking and the lung. Clin Rev Allergy Immunol. 1997;15:307-361.

16. Ellisen LW. Smoking and emphysema: the stress connection. Nat Med. 2010;16:754-755.

17. Ekberg-Jansson A, Bake B, Andersson B, et al. Respiratory symptoms relate to physiological changes and inflammatory markers reflecting central but not peripheral airways. A study in 0 year-old 'healthy' smokers and never-smokers. Respir Med. 2001;95:40-47.

18. Higenbottam T, Clark TJ, Shipley MJ, et al. Lung function and symptoms of cigarette smokers related to tar yield and number of cigarettes smoked. Lancet. 1980;1:409-411.

19. Eltayara L, Becklake MR, Volta CA, et al. Relationship between chronic dyspnea and expiratory flow limitation in patients with chronic obstructive pulmonary disease. Am J Respir Crit Care Med. 1996;154(6 Pt 1):1726-1734.

20. Gatta D, Fredi M, Aliprandi G, et al. Inspiratory drive is related to dynamic pulmonary hyperinflation in COPD patients. Int J Chron Obstruct Pulmon Dis. 2013;8:169-173.

21. Forey BA, Thornton AJ, Lee PN. Systematic review with meta-analysis of the epidemiological evidence relating smoking to COPD, chronic bronchitis and emphysema. BMC Pulm Med. 2011;11:36.

22. Kohansal R, Martinez-Camblor P, Agustí A, et al. The natural history of chronic airflow obstruction revisited. An analysis of the Framingham offspring cohort. Am J Respir Crit Care Med. 2009;180:3-10.

23. Rezende Gonçalves J, Corso Pereira M, et al. Severe obstructive disease: similarities and differences between smoker and non-smoker patients with COPD and/or bronchiectasis. Rev Port Pneumol. 2013;19: $13-18$.

24. Lee PN, Fry JS. Systematic review of the evidence relating FEV decline $_{1}$ to giving up smoking. BMC Med. 2010;8:84.

25. Brown CA, Crombie IK, Smith WC, Tunstall-Pedoe H. The impact of quitting smoking on symptoms of chronic bronchitis: results of the Scottish Heart Health Study. Thorax. 1991;46:112-116.

26. Willemse BW, Postma DS, Timens W, et al. The impact of smoking cessation on respiratory symptoms, lung function, airway hyperresponsiveness and inflammation. Eur Respir J. 2004;23: 464-476.

27. Pride NB. Smoking cessation: effects on symptoms, spirometry and future trends in COPD. Thorax. 2001;56:Suppl 2:II7-II10.

28. Liu SM, Zhou YM, Wang XP, et al. Biomass fuels are the probable risk factor for chronic obstructive pulmonary disease in rural South China. Thorax. 2007;62:889-897.

29. Chapman RS, He XZ, Blair AE, et al. Improvement in household stoves and risk of chronic obstructive pulmonary disease in Xuanwei, China: retrospective cohort study. BMJ. 2005;331:1050-1052.
International Journal of COPD

\section{Publish your work in this journal}

The International Journal of COPD is an international, peer-reviewed journal of therapeutics and pharmacology focusing on concise rapid reporting of clinical studies and reviews in COPD. Special focus is given to the pathophysiological processes underlying the disease, intervention programs, patient focused education, and self management protocols.

\section{Dovepress}

This journal is indexed on PubMed Central, MedLine and CAS. The manuscript management system is completely online and includes a very quick and fair peer-review system, which is all easy to use. Visit http://www.dovepress.com/testimonials.php to read real quotes from published authors. 